Family Profile No. 10, 2021

\title{
First Divorce Rate in the U.S., 2019
}

Author: Leslie Reynolds

In 2019, the overall U.S. divorce rate reached a forty-year low of 15.5 divorces per 1,000 married women (FP-20-25). However, the overall divorce rate includes divorces from both first marriages and higher-order marriages. Since first marriages are less likely to end in divorce than remarriages (Cohen, 2016), it is important to examine the first divorce rate separately. Using the 2019 American Community Survey 1-year estimates, we examine women's first divorce rate (defined as the number of first marriages that ended in divorce per 1,000 first marriages) among first married women 18 years and older. This Family Profile is an update to previous profiles on the first divorce rate (FP-20-02, FP-18-15, FP-16-19, FP-14-09, FP-11-09, and FP-10-06).

Trends in the First Divorce Rate

- The first divorce rate has decreased overall since 2008.

- After the divorce rate plateaued from 2009 to 2012, the first divorce rate declined to 14.9 divorces per 1,000 women in a first marriage in 2018 and remained at this 10-year low in 2019.

- An estimated 741,163 women experienced a first divorce in 2019.

Figure 1. First Divorce Rate for Women 18 and Older, 2008-2019

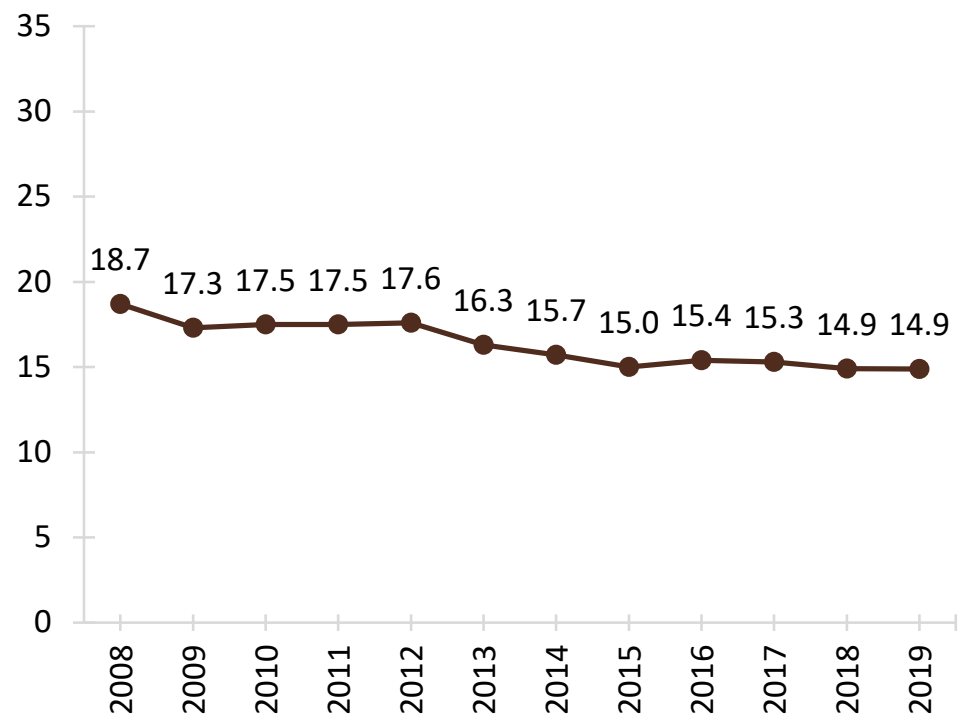

Source: NCFMR analyses of U.S. Census Bureau, American Community Survey, 1-yr. est., 2019

First Divorce Rate by Race and Ethnicity

Figure 2. First Divorce Rate for Women 18 and Older by Race and Ethnicity, 2019

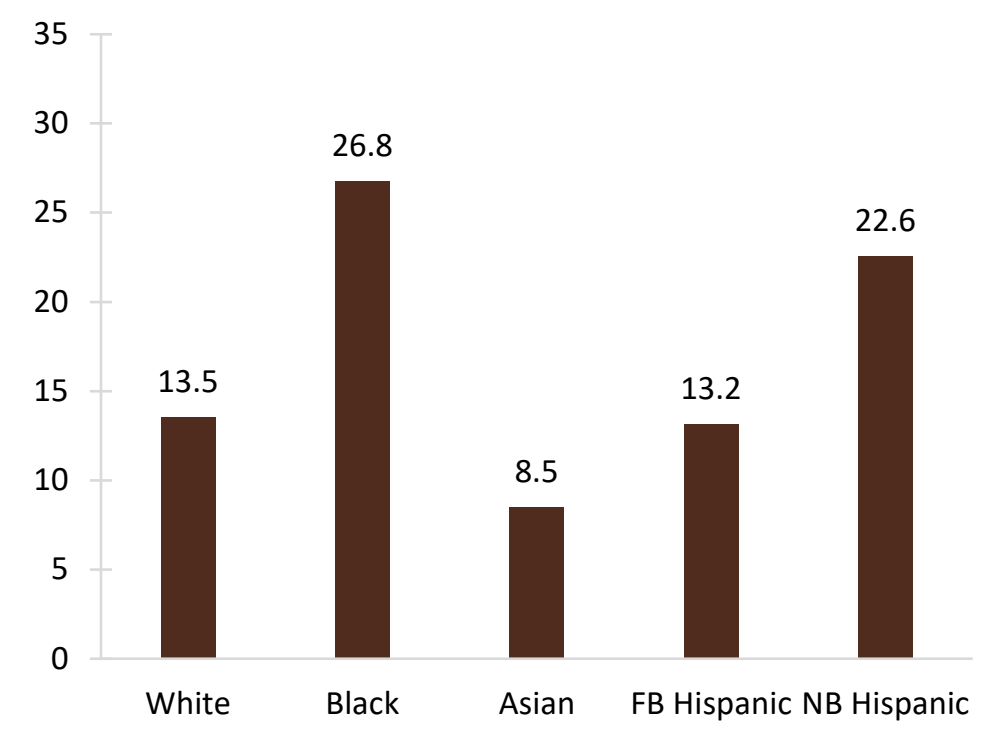

- In 2019, Black women experienced the highest first divorce rate (26.8).

- Asian women had the lowest first divorce rate (8.5).

- There was a nativity gap among Hispanics, with nativeborn Hispanics having a higher first divorce rate (22.6) than foreign-born Hispanics (13.2).

Source: NCFMR analyses of U.S. Census Bureau, American Community Survey, 1-yr. est., 2019 
First Divorce Rate by Educational Attainment

- Women with some college education but no degree (18.7) and women with an associate's degree (17.0) had the highest first divorce rates.

- The lowest first divorce rates were observed among women with a bachelor's degree (13.2) and women with a master's degree or higher (11.5).

Figure 3. First Divorce Rate for Women 18 and Older by Educational Attainment, 2019

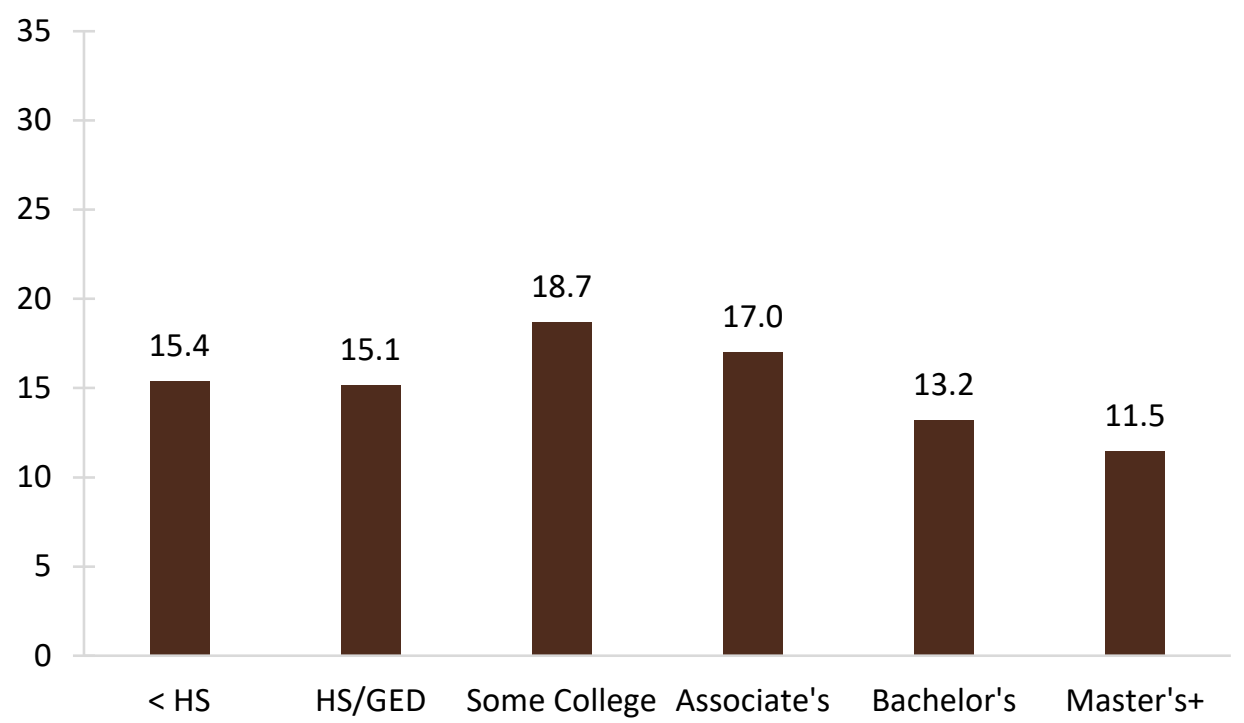

Source: NCFMR analyses of U.S. Census Bureau, American Community Survey, 1-yr. est., 2019

References:

Allred, C. (2019). Divorce rate in the U.S.: Geographic variation, 2018. Family Profiles, FP-19-23. Bowling Green, OH: National Center for Family \& Marriage Research. https://doi.org/10.25035/ncfmr/fp-19-23

Allred, C. \& Schweizer, V. J. (2020). First Divorce Rate in the U.S., 2018. Family Profiles, FP-20-02. Bowling Green, OH: National Center for Family \& Marriage Research. https://doi.org/10.25035/ncfmr/fp-20-02

Anderson, L. R. (2016). First divorce rate in the U.S., 2014. Family Profiles, FP-16-19. Bowling Green, OH: National Center for Family \& Marriage Research. https://www.bgsu.edu/ncfmr/resources/data/family-profiles/anderson-first-divorce-rate-2014-fp-16-19.html

Cohen, P. N. (2016). Multiple-decrement life tables from 2010-2012 American Community Survey data marital events. Retrieved from https://familyinequality.wordpress.com/2016/06/08/life-table-says-divorce-rate-is-52-7/

Gibbs, L. \& Payne, K. K. (2011). First divorce rate, 2010. Family Profiles, FP-11-09. Bowling Green, OH: National Center for Family \& Marriage Research. http://www.bgsu.edu/content/dam/BGSU/college-of-arts-and-sciences/NCFMR/documents/FP/FP-11-09.pdf

Payne, K. K. (2011). First divorces in the U.S., 2008. Family Profiles, FP-10-06. Bowling Green, OH: National Center for Family \& Marriage

Research. http://www.bgsu.edu/content/dam/BGSU/college-of-arts-and-sciences/NCFMR/documents/FP/FP-10-06.pdf

Payne, K. K. (2018). First divorce rate in the U.S., 2016. Family Profiles, FP-18-15. Bowling Green, OH: National Center for Family \& Marriage Research. https://doi.org/10.25035/ncfmr/fp-18-15

Reynolds, L. (2020). Divorce rate in the U.S.: Geographic variation, 2019. Family Profiles, FP-20-25. Bowling Green, OH: National Center for Family \& Marriage Research. https://doi.org/10.25035/ncfmr/fp-20-25

Stykes, B., Gibbs, L., \& Payne, K. K. (2014). First divorce rate, 2012. Family Profiles, FP-14-09. Bowling Green, OH: National Center for Family \& Marriage Research. http://www.bgsu.edu/content/dam/BGSU/college-of-arts-and-sciences/NCFMR/documents/FP/FP-14-09-divorcerate-2012.pdf

\section{Suggested Citation}

Reynolds, L. (2021). First divorce rate in the U.S., 2019. Family Profiles, FP-21-10. Bowling Green, OH: National Center for Family \& Marriage Research. https://doi.org/10.25035/ncfmr/fp-21-10 